\title{
ANALISIS TITIK IMPAS PEMBUATAN SIRUP PEDADA (Sonneratia caseolaris L) POJOK SADAR WISATA TIRAM TAMBUN DI KELURAHAN MENTAWIR
}

\author{
Rochadi Kristiningrum ${ }^{1}$, Wulan I R Sari², Abubakar M. Lahjie ${ }^{3}$, Yosep Ruslim ${ }^{4}$ \\ ${ }_{1,3,4}$ Dosen Fakultas Kehutanan Universitas Mulawarman Samarinda 75118, Indonesia \\ ${ }^{2}$ Dosen Fakultas Ekonomi dan Bisnis Universitas Mulawarman Samarinda 75118 \\ E-Mail: rkristiningrum@fahutan.unmul.ac.id \\ E-Mail: wulan.sari@feb.unmul.ac.id \\ Email: yruslim@fahutan.unmul.ac.id
}

\begin{abstract}
ABSTRAK
Analisis Titik Impas Pembuatan Sirup Pedada (Sonneratia caseolaris L) Pojok Sadar Wisata Tiram Tambun di Kelurahan Mentawir. Pemanfaatan hasil hutan mangrove di Kelurahan Mentawir masih sangat terbatas. Salah satu jenis mangrove yang bisa dimanfaatkan untuk kebutuhan pangan adalah jenis Sonneratia caseolaris L) atau pedada. Jenis ini bisa dimanfaatkan sebagai bahan pembuatan sirup, dodol/jenang mangrove, roti atau bedak dingin agar memiliki nilai tambah secara ekonomis bagi masyarakat sekitar ekosistem mangrove. Tujuan penelitian ini adalah untuk mengetahui cara pembuatan sirup mangrove, mengetahui besarnya biaya dan titik impas usahanya bagi Pojok Sadar Wisata Tiram Tambun di Kelurahan Mentawir. Pengambilan sampelnya menggunakan purposive sampling yaitu kepada pojok sadar wisata tiram Tambun. Metode penelitianya secara dekriptif kualitatif, analisis biaya, pendapatan dan Break even point dengan jumlah produksi 100 botol dan 300 botol. Proses pembuatan sirup pedada (S. caseolaris L) meliputi persiapan alat dan bahan, pencucian buah pedada, penghancuran/penumbukan, pengambilan sari buah pedada, pemasakan/perebusan, pendinginan dan pengemasan sirup dalam botol. Biaya tetap pembuatan sirup sebesar Rp.750.00 per periode baik untuk produksi 100 dan 300 botol. Sedangkan biaya variabel untuk 100 dan 300 botol berturut-turut sebesar Rp.942.000 dan Rp.2.272.800 selama satu periode. Titik impas quantity dan harga pada produksi sirup 100 botol berturut-turut sebesar 71 botol dan Rp.14.178. Sedangkan titik impas quantity dan harga pada produksi sirup 300 botol berturut-turut sebesar 89 botol dan Rp.4.748. Hal ini berarti produksi sirup 300 botol lebih menguntungkan daripada memproduksi 100 botol.
\end{abstract}

Kata kunci : Mentawir, Pedada, Titik Impas.

\begin{abstract}
Analysis of the Break Even Point for Making Pedad (Sonneratia caseolaris L) Syrup Tiram Tambun Tourist Conscious Corner in Mentawir Village. The utilization of mangrove forest products in Mentawir Village is still very limited. One type of mangrove that can be used for food needs is the type of pedada (Sonneratia caseolaris L). This type can be used as an ingredient in making syrup, dodol mangrove, bread or cold powder so that it has added value economically for the people around the mangrove ecosystem. The purpose of this research was to determine how to make mangrove syrup, to know the cost and break-even point for the Tiram Tambun Tourism Conscious Corner in Mentawir Village. The research method is descriptive qualitative, cost analysis, income and break even point with a total production of 100 and 300 bottles. The process of making pedada (S. caseolaris L) syrup includes preparation of tools and ingredients, washing of pedada fruits, crushing, extracting pedada fruit juice, cooking/boiling, cooling and packaging the syrup in bottles. The fixed cost of making syrup is IDR 750.00 per period for both 100 and 300 bottles production. Meanwhile, the variable costs for 100 and 300 bottles were Rp,942,000 and Rp,2,272,800, respectively for one period. The break-even point quantity and price for the production of 100 bottles of syrup are 71 bottles and Rp,14.178, respectively. Meanwhile, the break-even point quantity and price in the production of 300 bottles of syrup are 89 bottles and Rp, 4,748, respectively. This means that producing 300 bottles of syrup is more profitable than producing 100 bottles.
\end{abstract}

Key words : Break Even Point, Mentawir, Pedada. 


\section{PENDAHULUAN}

Provinsi Kalimantan Timur merupakan salah satu provinsi yang memiliki sumber daya yang melimpah baik gas, minyak, batubara dan sumber daya yang lainnya seperti hutan mangrove. Kelurahan Mentawir adalah salah satu kelurahan yang berada di Kecamatan Sepaku Kabupaten Kutai Kartanegara yang memiliki luas daratan sebesar 22.222 ha dan hutan mangrove seluas 2.300 ha (Kristiningrum, 2020) yang memiliki fungsi dan peranan yang beraneka ragam bagi mahkluk hidup lainnya.

Wahyukinasis et al (2014) menyatakan bahwa aneka produk yang berasal dari mangrove telah banyak di rasakan oleh manusia. Produk tersebit berupa hasil kayu dan hasil non kayu. Pada awalnya masyarakat hanya memanfaatkan mangrove untuk di ambil kayunya sebagai bahan bakar upacara adat, untuk memasak, bahan bangunan dan pembuatan kapal. Namun dengan berkembangnya zaman, ternyata buah mangrove bisa sebagai penghasil pangan.

Pengusahaan olahan pangan yang berasal dari mangrove masih sedikit yang mengusahakan dan belum diminati oleh masyarakat pesisir (Dewi et.al, 2014 dan Priyono et al, 2010). Masyarakat masih banyak yang kurang tahu kalau buah mangrove bisa di konsumsi dan kulit pohonnya bisa dijadikan pewarna kain (Herwanti, 2014). Salah satu olahan pangan dengan menggunakan bahan baku mangrove adalah buah pedada (Sonneratia caseolaris) yang kaya akan kandungan vitamin A, B1, B2 dan C (Manalu et al, 2013 dan Syaparuddin, 2013).

Pojok Sadar Wisata (Pokdarwis) sejak tahun 2016 telah mengembangkan usaha pembuatan sirup pedada. Hal ini disebabkan karena terdapat bahan baku yang melimpan di wilayah tersebut. Hal ini sesuai dengan penelitian yang dilakukan oleh Kristiningrum et.al (2019), bahwa terdapat 12 jenis mangrove di Kelurahan Mentawir dan salah satunya terdapat jenis Sonneratia caseolaris dan Sonneratia alba. Kedua jenis tersebit bisa dimanfaatkan sebagai bahan baku pembuatan sirup. Oleh masyarkat sekitar, sirup ini diyakini memberikan manfaat yang besar bagi kesehatan. Salah satu contohnya adalah sebagai obat kebugaran, meningkatkan stamina dan menambah nafsu makan dan libido. Hal ini selaras dengan pernyataan dari Herwanti (2015). Selain itu sirup mangrove memiliki asam dan segar yang banyak diminati oleh masyarakat apalagi disaat cuaca sangat panas.

Sirup mangrove yang berasal dari buah pedada merupakan salah satu produk unggulan dari Kelompok Sadar Wisata (Pokdarwis) Tiram Tambun selain jenang mangrove dan bedak mangrove. Usaha tersebut diharapakn bisa menambah pendapatan dan meningkatkan perekonomian masyarakat di daerah sekitar mangrove. Atas dasar itulah kiranya perlu dilakukan penelitian terkait analisis titik impas pembuatan sirup pedada Pokdarwis Tiram Tambun di Kelurahan Mentawir.

\section{METODA PENELITIAN}

\subsection{Tempat dan Waktu}

Penelitian dilaksanakan di Kelurahan Mentawir Kecamatan Sepaku. Pada bulan Maret-Mei 2020.

\subsection{Bahan dan Alat}

Bahan yang digunakan adalah buah pedada (Sonneratia caseolaris), gula dan air. Sedangkan alat yang digunakan adalah pisau, keranjang, ember, telenan, penumbuk, panci, kompor gas, gas, karung goni, 
gatung, panci, botol kemasan, label, alat tulis dan kamera.

\subsection{Rancangan Penelitian}

Data yang telah di dapat meliputi data primer dan data sekunder dengan responden di pilih secara purposive sampling adalah kelompok sadar wisata tiram tambun dimana mereka melakukan produksi pembuatan sirup sebanyak 100 botol dan 300 botol dengan alasan untuk membandingkan nilai titik impasnya yaitu break even point (BEP) quantity dan BEP harga.

\subsection{Prosedur Pelaksanaan Penelitian}

Analisis data yang di gunakan adalah:

1) Analisis Deskriptif, digunakan untuk menjelaskan dan menggambarkan proses pembuatan sirup yang menggunakan bahan buah

$$
\begin{aligned}
& \text { mangrove pedada } \\
& \text { caseolaris). }
\end{aligned}
$$

2) Analisis Kuantitatif, digunakan untuk mengetahui besar biaya tetap dan variabel dari pembuatan sirup buah mangrove. Masing-masing biaya yang dikeluarkan dipilah-pilah apakah termasuk biaya tetap ataukah biaya variabel dan kemudian biaya-biaya tersebut dijumlahkan sesuai jenis biayanya apakan masuk dalam biaya tetap ataukah biaya variabel.

3) Analisis Deskriptif Kuantitatif, digunakan untuk menganalisis nilai Break Even Point (BEP) dari penjualan pupuk organik.

Untuk mencari nilai break even point dalam unit yang dihitung dengan menggunakan rumus dibawah ini:

$$
B \mathrm{EP}_{(q)}=\frac{\mathrm{FC}}{P-\lceil\mid \mathrm{VC}\rceil\rceil}
$$

$\begin{array}{ll}\operatorname{Dimana:}_{(q)} & \\ \operatorname{BEP}_{(q)} & =\text { Break Even Point } \\ \text { FC } & \text { = Total biaya tetap } \\ \text { VC } & =\text { Total biaya variabel } \\ \mathrm{P} & =\text { Harga jual per unit }\end{array}$

Sedangkan perhitungan break even point dalam rupiah adalah:

$$
\mathrm{BEP}_{(\mathrm{Rp})}=\frac{\mathrm{FC}}{1-\left[\left[\frac{\mathrm{VC}}{\mathrm{S}}\right]\right]}
$$

Dimana:

$$
\begin{aligned}
& \mathrm{BEP}_{(\mathrm{Rp})} \quad=\text { Break even point } \\
& \mathrm{FC} \quad=\text { Total biaya tetap }(\mathrm{Rp}) \\
& \mathrm{VC} \quad=\text { Total biaya variabel }(\mathrm{Rp}) \\
& \mathrm{S} \quad \quad=\text { Nilai Penjualan }(\mathrm{Rp})
\end{aligned}
$$

\section{HASIL PENELITIAN DAN PEMBAHASAN}

\subsection{Proses Pembuatan Sirup Pedada}

Salah satu buah mangrove yang bisa dimanfaatkan untuk membuat sirup adalah jenis Sonneratia caseolaris atau yang sering di sebut dengan buah pedada. 
Jenis mangrove ini selain bisa dimanfaatkan untuk membuat siriup, bisa juga di manfaatkan untuk bahan pembuatan jenang mangrove, roti brownis dan bedak dingin.

Dalam perkembangan, prospek pengembangan usaha pembuatan sirup mangrove yang dilakukan oleh Pokdarwis Tiram Tambun memiliki peluang yang sangat cerah. Hal ini dapat dilihat dari makin meningkanya permintaan akan sirup mangrove di berbagai acara. Hal ini selaras dengan Sabana (2014) yang menyatakan bahwa sirup mangrove di Semarang memiliki prospek yang bagus untuk dikembang.

Jenis buah ini menurut menurut Agustinus (2019) dapat berbuat sebanyak 2 kali dalam setahun dan dapat dijadikan sebagai bahan pangan masyarakat sekitar. Sedangkan menurut Pradita (2018) yang mengatakan bahwa produksi sirup pedada berbeda dengan kerupuk jeruju yang produksinya selalu dilakukan sepanjang tahun, hal ini karena pohon pedada yang berbuah secara musiman sehingga produksinya juga dilakukan secara musiman berbeda dengan daun jeruju yang selalu tersedia untuk di produksi.

Menurut Andriani, et al., (2015)

Buah Sonneratia caseolaris memiliki beberapa keunggulan dibandingkan dengan jenis tanaman mangrove lainnya yaitu sifat buahnya tidak beracun, dapat dimakan langsung, rasa asam dan aroma yang khas serta tekstur buah yang lembut membuat buah Sonneratia caseolaris cocok diolah untuk dijadikan beberapa produk pangan seperti jenang, dodol, selai dan sirup. Menurut Kristiningrum, et.al (2020), nilai guna langsung ekosistem mangrove yang ada di Kelurahan Mentawir salah satunya adalah berfungsi sebagai penyedia bahan baku dan penghasil bahan pangan yaitu sebagai penyedia bahan baku pembuatan sirup, dodol, selai, bedak dingin dan kue brownis.

Proses pembuatan sirup pedada yang di lakukan oleh kelompok sadar wisata "Tiram Tambun" di Kelurahan Mentawir tergolong masih sangat sederhana. Dimana bahan baku buah pedada dapat dengan mudah di dapat di sekitar tempat tinggal mengingat dareah pemukiman penduduk dekat dengan ekosistem mangrove dan pelatan yang di gunakan untuk membuat sirup itu mudah di dapat dan hampir semuanya merupakan alat masak rumah tangga. Buah pedada adalah buah yang bentuknya seperti buah apel dan berwarna hijau. Buah yang dapatkan dari hutan kemudian di bersihakan dan dicuci. Setelah di cuci langkah selanjutnya dalah di tumpuk atau di hancurkan menggunakan alat penumbuk untuk di ambil sarinya. Setelah ditumbuk, maka di tambahkan air secukupnya untuk di lakukan pemerasan sari buah pedada. Proses ini bisa dilakukan sebanyak lima kali hingga sari dari buah pedada tersebut habis. Hasil sari buah pedada tersebt kemudian di rebus dan di tambahi dengan air sesuai dengan yang dikehendaki . Saat perebusan, langkah selanjtnya dalah ditambahkan gula sebagai pemanis buatan. Perbandingan antara gula dengan air adalah 1: 2. Jadi misalkan airnya 20 liter, maka gula yang ditambahan adalah $10 \mathrm{~kg}$. Setelah gula larut dalam air dan sari buah pedada, maka di tunggu hingga mendidih sambil diaduk-aduk agar gula tercampur dengan baik. Setelah larutan sirup mendidih, maka api di matikan dan larutan di dinginkan sebentar. Jika larutan sirup sudah dingin, maka sirup siap untuk di kemas dalam botol dan dipasarkan. Seperti pada gambar di bawah ini. 

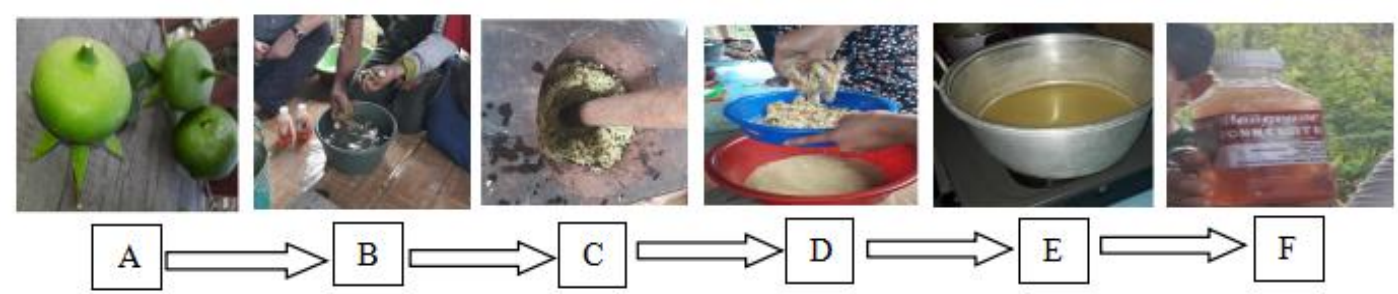

Gambar 1. Proses Pembuatan Sirup Pedada

Keterangan Gambar:

A : Buah pedada ( $S$. caseolaris;, B : Proses Pembersihan buah pedada; C : Proses penghancuran/penumbukan; D : Proses pemerasan buah pedada; E : Proses perebusan; F : Sirup pedada siap di pasarkan.

\subsection{Analisis Biaya Pembuatan Sirup \\ Pedada}

Biaya pembuatan sirup pedada adalah semua biaya yang di keluarkan untuk membiayai kegiatan pembuatan sirup tersebut baik meliputi biaya tetap ataupun biaya variabel. Hal tersebut sesuai dengan pernyataan Sopiannur et.al. (2011), yaitu biaya produksi digunakan untuk membiayai semua kegiatan usaha tersebut. Sedangkan biaya tetap adalah biaya yang besar kecilnya tidak dipengaruhi oleh besarnya produksi dan biaya variabel adalah biaya yang besar

kecilnya di pengaruhi oleh volume produksi (Daniel, 2004).

Yang di maksud dengan biaya tetap dalam penelitian ini adalah biaya penyusutan peralatan yang di gunakan setiap melakukan proses produksi. Hal tersebut merujuk penelitian yang di lakukan oleh Agustinus (2019). Adapun rincian biaya tetap pembuatan sirup pedada sebagaimana dalam tabel di bawah ini.

Tabel 1. Rincian Biaya Tetap

\begin{tabular}{|c|c|c|c|c|}
\hline No & Uraian & Total & $\begin{array}{c}\text { Masa Pakai } \\
\quad \text { (tahun) }\end{array}$ & Biaya Penyusutan \\
\hline 1 & Pisau besar/golok & 50.000 & 5 & 10.000 \\
\hline 2 & Keranjang & 50.000 & 3 & 16.667 \\
\hline 3 & Ember kecil & 135.000 & 3 & 45.000 \\
\hline 4 & Ember besar & 320.000 & 3 & 106.667 \\
\hline 5 & Pisau kecil & 50.000 & 5 & 10.000 \\
\hline 6 & Telenan & 75.000 & 3 & 25.000 \\
\hline 7 & Penumbuk & 250.000 & 5 & 50.000 \\
\hline 8 & Penyaring & 30.000 & 3 & 10.000 \\
\hline 9 & Gayung & 20.000 & 3 & 6.667 \\
\hline 10 & Panci Perebusan & 300.000 & 3 & 100.000 \\
\hline 11 & Panci Perendaman & 300.000 & 3 & 100.000 \\
\hline 12 & Kompor gas & 400.000 & 5 & 80.000 \\
\hline 13 & Gas & 150.000 & 5 & 30.000 \\
\hline 14 & Sutil pengaduk & 10.000 & 2 & 5.000 \\
\hline 15 & Corong & 10.000 & 2 & 5.000 \\
\hline \multirow[t]{2}{*}{18} & Kulkas & 1.500 .000 & 10 & 150.000 \\
\hline & & Jumlah & & 750.000 \\
\hline
\end{tabular}


Berdasarkan tabel diatas dapat dijelaskan bahwa biaya tetap yang dikeluarkan dalam proses pembuatan sirup sebesar Rp.750.000 dalam satu kali proses produksi baik dalam memproduksi 100 botol maupun 300 botol sirup. Dimana peralatan yang digunakan meliputi pisau besar/golok, keranjang, ember, pisau kecil, telenan, penumbuk, penyaring, gayung, panci, kompor gas, gas LPG, sutil pengaduk, corong dan kulkas.

Dalam penelitian ini dilakukan pembuatan sirup pedada sebanyak 100 botol dan 300 botol. Adapun rincian biaya variabel pembuatan sirup sebanyak 100 botol sebagai berikut:

Tabel 2. Biaya Varibel Pembuatan Sirup 100 Botol

\begin{tabular}{|c|c|c|c|c|c|}
\hline No & Uraian & Q & Harga & Total & Satuan \\
\hline 1 & Buah pedada & 50 & 3.000 & 150.000 & $\mathrm{Kg}$ \\
\hline 2 & Air & 20 & 100 & 2.000 & Liter \\
\hline 3 & Gula & 10 & 12.000 & 120.000 & $\mathrm{~kg}$ \\
\hline 4 & Karung goni & 10 & 2.500 & 25.000 & pcs \\
\hline 5 & Bensin untuk Transportasi & 4 & 10.000 & 40.000 & trip \\
\hline 6 & Tenaga kerja & 4 & 75.000 & 300.000 & HOK \\
\hline 7 & Listrik & 1 & 100.000 & 100.000 & bln \\
\hline 8 & Botol kemasan & 100 & 2.000 & 200.000 & pcs \\
\hline 9 & Label & 100 & 50 & 5.000 & pcs \\
\hline
\end{tabular}

Berdasarkan tabel diatas dapat dijelaskan bahwa untuk memproduksi 100 botol sirup buah pedada membutuhkan biaya variabel sebesar Rp.942.000 dimana buah pedada yang dibutuhkan sebanyak $50 \mathrm{~kg}$, air 20 liter, gula $10 \mathrm{~kg}$, karung goni $10 \mathrm{pcs}$, bensin untuk transportasi 4 liter, tenaga kerja sebanyak 4 orang, botol kemasan dan label sebanyak 100 pcs.

Adapun biaya variabel yang dibutuhkan untuk menghasilkan 300 botol sirup pedada sebagai berikut:

Tabel 3. Biaya Variabel Pembuatan Sirup 300 Botol

\begin{tabular}{llcrrc}
\hline No & Uraian & Quantity & Harga & \multicolumn{1}{c}{ Total } & \multicolumn{2}{c}{ Satuan } \\
\hline 1 & Buah pedada & 150 & 2400 & 360.000 & $\mathrm{Kg}$ \\
2 & Air & 60 & 80 & 4.800 & liter \\
3 & Gula & 30 & 9600 & 288.000 & $\mathrm{~kg}$ \\
4 & Karung goni & 30 & 2000 & 60.000 & $\mathrm{pcs}$ \\
5 & Bensin untuk Transportasi & 6 & 8000 & 48.000 & trip \\
6 & Biaya tenaga kerja & 12 & 60000 & 720.000 & $\mathrm{HOK}$ \\
7 & Listrik & 3 & 100.000 & 300.000 & $\mathrm{kwh}$ \\
8 & Botol kemasan & 300 & 1600 & 480.000 & $\mathrm{pcs}$ \\
9 & Label & 300 & 40 & 12.000 & $\mathrm{pcs}$ \\
\hline
\end{tabular}

Berdasarkan tabel diatas dapat dijelaskan bahwa untuk memproduksi 100 botol sirup buah pedada membutuhkan biaya variabel sebesar Rp.2.272.800 dimana buah pedada yang dibutuhkan sebanyak $150 \mathrm{~kg}$, air 60 liter, 
gula $30 \mathrm{~kg}$, karung goni 30 pcs, bensin untuk transportasi sebesar 6 liter, tenaga kerja sebanyak 12 orang, botol kemasan dan label sebanyak 300 pcs.

\subsection{Break Even Point Pembuatan Sirup}

Analisa titik impas atau sering disebut dengan break even point (BEP) adalah analisis yang digunakan untuk melihat suatu usaha pada suatu harga tertentu dan jumlah tertentu tidak akan mengalami kerugian atau menghasilkan keuntungan atau dengan kata lain, usaha tersebut tidak untung atau tidak rugi.

Perhitungan biaya-biaya yang di keluarkan untuk memproduksi pembuatan sirup baik 100 botol maupun 300 botol dapat dijadikan sebagai acuan dalam perhitungan break event point yaitu meliputi biaya tetap (FC), biaya variabel (VC), harga jual per unit $(\mathrm{P})$, volume produksi $(\mathrm{Q})$ dan total penjualan (S).

Adapun rekapitulasi rincian biaya yang di keluarkan untuk memproduksi sirup 100 botol dan sebagai berikut:

Tabel 4. Rekapitulasi Biaya dan Penjualan Sirup 100 Botol

\begin{tabular}{clrc}
\hline No & \multicolumn{1}{c}{ Uraian } & Nominal & Persentase (\%) \\
\hline 1 & Biaya Tetap (FC) & 750.000 & 44,33 \\
2 & Biaya Variabel (VC) & 942.000 & 55,67 \\
3 & Biaya total (TC) & 1.692 .000 & \\
4 & Volume produksi (Q) & 100 & \\
5 & Harga jual per unit(P) & 20.000 & \\
6 & Total penjualan (S) & 2.000 .000 & \\
\hline
\end{tabular}

Berdasarkan data diatas ternyata biaya tetap memiliki prosentase sebesar $44,33 \%$, sedangkan biaya variabel sebesar $55,67 \%$. Hal ini berarti biaya variabel lebih besar daripada biaya tetap. Dengan volume produksi sirup sebesar 100 botol dan harga sirup per botol sebesar Rp.20.000, maka total penjualanya sebesar Rp.2.000.000.

Sedangkan rekapitulasi rincian biaya yang di keluarkan untuk memproduksi sirup 300 botol dan sebagai berikut:

Tabel 5. Rekapitulasi Biaya dan Penjualan Sirup 300 Botol

\begin{tabular}{clrc}
\hline No & \multicolumn{1}{c}{ Uraian } & Nominal & Persentase \\
\hline 1 & Biaya Tetap (FC) & 750.000 & 24,81 \\
2 & Biaya Variabel (VC) & 2.272 .800 & 75,19 \\
3 & Biaya total (TC) & 3.022 .800 & \\
4 & Volume produksi (Q) & 300 & \\
5 & Harga jual per unit(P) & 16.000 & \\
6 & Total penjualan (S) & 4.800 .000 & \\
\hline
\end{tabular}

Berdasarkan data diatas ternyata biaya tetap memiliki prosentase sebesar $24,81 \%$, sedangkan biaya variabel sebesar $75,19 \%$. Hal ini berarti biaya variabel lebih besar daripada biaya tetap. Dengan volume produksi sirup sebesar
300 botol dan harga sirup per botol sebesar Rp.16.000, maka total penjualanya sebesar Rp.4.800.000.

Atas dasar Tabel 4 dan Tabel 5 diatas, maka analisis titik impas 
pembuatan sirup pedada dapat dilihat pada tabel dibawah ini.

Tabel 6. Hasil Rekapitulasi BEP Pembuatan Sirup 100 Botol dan 300 Botol

\begin{tabular}{cccrr}
\hline No & Produksi & BEP $(\mathrm{q})$ & BEP $(\mathrm{Rp})$ & \multicolumn{2}{c}{ Laba/produksi } \\
\hline 1 & $100 \mathrm{btl}$ & 71 & 14.178 & 582.231 \\
2 & $300 \mathrm{btl}$ & 89 & 4.748 & 3.375 .499 \\
\hline
\end{tabular}

Berdasarkan tabel diatas dapat dijelaskan bahwa jika memproduksi sirup pedada sebanyak 100 botol dengan harga jual per botol sebesar Rp.20.000, maka BEP (q) nya sebesar 71 dan BEP (Rp) sebesar Rp.14.178, sedangkan keuntungan yang diperoleh dalam satu periode produksi sirup menghasilkan laba sebesar Rp.582.231. Hal ini selaras dengan penelitian yang dilakukan Tarihora et al (2012) yang melakukan perhitungan BEP dimana dalam memproduksi sirup pedada sebanyak 100 botol, ternyata menghasilkan BEP (q) sebesar 72 .

Jika memproduksi sirup pedada sebanyak 300 botol dengan harga jual per botol sebesar Rp.16.000, maka BEP (q) nya sebesar 89 dan BEP (Rp) sebesar Rp.4.748, sedangkan keuntungan yang diperoleh dalam satu periode produksi sirup menghasilkan laba sebesar Rp.3.375.499.

Dari data tersebut diatas maka dapat disimpulkan bahwa lebih baik memproduksi sirup dalam jumlah besar. Hal ini terbukti bahwa jika kita memproduksi 300 botol, maka keuntunganya adalah enam kali lipat lebih besar daripada kita memproduksi sirup sebanyak 100 botol. Hal ini disebabkan karena biaya variabel yang dikeluarkan lebih murah dalam memproduksi sirup dalam jumlah banyak, daripada memproduksi sirup di bawah 300 botol. Hal ini berarti usaha pembuatan sirup dari buah pedada layak untuk di usahakan setelah dilakukan uji titik impas dan hal ini sejalan dengan penelitian yang dilakukan oleh
Wahyukinasih et.al (2014) yang menyatakan bahwa usaha pembuatan sirup buah pedada menghasilkan $\mathrm{B} / \mathrm{C}$ ratio diatas 1 .

\section{KESIMPULAN}

Kesimpulan dari hasil penelitian adalah sebagai berikut : Proses pembuatan sirup melalui berbagai macam tahapan antara lain seperti: persiapan alat dan bahan, penghancuran buah pedada, pengambilan sari buah pedada dengan cara di saring. Setelah itu perebusan sari buah pedada bersama dengan air dan gula. Langkah selanjutnya adalah di dinginkan dan siap di kemas dalam botol dan di pasarkan.

Biaya tetap yang dikeluarkan dalam pembuatan sirup buah pepada sebesar Rp.750.000 per periode baik untuk produksi 100 dan 300 botol. Sedangkan biaya variabel yang dikeluarkan pada pembuatan sirup sebanyak 100 dan 300 botol berturut-turut sebesar Rp.942.000 Rp.2.272.800 selama satu periode.

Titik impas pada produksi pembuatan sirup sebanyak 100 botol dengan mendapatkan keuntungan sebesar Rp.582.231 per periode. Sedangkan titik impas pada produksi pembuatan sirup sebanyak 300 botol dengan mendapatkan keuntungan sebesar Rp.3.375.499 per periode.

\section{UCAPAN TERIMA KASIH}

Ucapan terima kasih kami sampaikan kepada Kementerian Ristek BRIN atas 
dana hibah disertasi yang penulis dapatkan pada tahun 2020 sehingga dapat memperlancar pelaksanaan penelitian dan Bapak Lamale selaku Ketua Pokdarwis Tiram Tambun yang telah banyak membantu selama penelitian.

\section{DAFTAR PUSTAKA}

Agustinus, R.P. (2019). Analisis Finansial dan Pemasaran Produk Olahan Syrup Pedada (Sonneratia caseolaris L) Di Kecamatan Perbaungan Kabupaten Serdang Dedagai Sumatera Utara. Skrpsi. Medan: Universitas Sumatera Utara.

Andriani, D. (2015). Mutu Sirup Buah Pedada (Sonneratia caseolaris) Selama Penyimpanan Dengan Penambahan Natrium Benzoat. Jurusan Teknologi Pertanian. Pekanbaru: Universitas Riau.

Daniel, M. (2004). Pengantar Ekonomi Pertanian. Jakarta: Bumi Aksara.

Dewi PDP, Sukerti NW, Ekayani IAPH. (2014). Pemanfaatan Tepung Buah Mangrove Jenis Lindur (Bruguiera Gymnorrizha) Menjadi Kue Kering Putri Salju. Bosaparis, (2)1, 1-10.

Herwanti, S. (2015). Kajian Pengembangan Usaha Sirup Mangrove di Desa Margasari Kecamatan Labuhan Maringgai Kabupaten Lampung Timur. Jurnal Hutan Tropis, 4(1), 35-50.

Manalu RDE, Salamah E, Retiaty F, Kurniawati N. (2013). Kandungan Zat Gizi Makro Dan Vitamin Produk Buah Pidada (Sonneratia Caseolaris). Penelitian Gizi dan Makanan (36)2, 135-140.

Kristiningrum, R. (2020). Keanekaragaman dan Valuasi Ekonomi Ekosistem Mangrove di Kelurahan Mentawir Kabupaten
Penajam Paser Utara Provinsi Kalimantan Timur. Disertasi. Samarinda: Universitas Mulawarman.

Kristiningrum R, Lahjie AM, Masjaya, Yusuf S, Ruslim Y, Ma'ruf A. (2020). Fauna Diversity, Productivity Potential and Total Economic Value of Mangrove Ecosystems in Mentawir Village, East Kalimantan, Indonesia. Biodiversity, 21(5), 1940-1953.

Kristiningrum R, Lahjie AM, Masjaya, Yusuf S, Ruslim Y. (2019). Species Diversity, Stand Productivity, Above Ground Biomass, and Economic Value of Mangrove Ecosystem in Mentawir Village, East Kalimantan, Indonesia. Biodiversity, 20(10), 2848-2857.

Pradita, Adisti Yulia. (2018). Analisis Kelayakan Finansial Dan Nilai Tambah Pengolahan Tanaman Mangrove di Kampung Nipah Desa Sei Nagalawan Kabupaten

Serdang Bedagai. Skripsi. Medan: Universitas Sumatera Utara.

Priyono A, Ilminingtyas D, Mohson, Yuliani LS, Hakim TL. (2010). Beragam produk lahan berbahan dasar mangrove. Semarang: Kesemat.

Sabana, C. (2014). Kajian Pengembangan Produk Makanan Olahan Mangrove. Jurnal Ekonomi dan Bisnis, (14)1, 40-46.

Tarihora I, Purwoko A, Hartini, KS. (2012). Kajian Pengelolaan Buah Berembang (Sonneratia caseolaris) sebagai Bahan Makanan dan Minuman di Kabupaten Deli Serdang. Medan: Sumatera Utara.

Sopianur, Rita, Juraemi. (2011). Studi Pendapatan Usaha Gula Aren Ditinjau dari Jenis Bahan Bakar di 
Dusun Girirejo Kelurahan Lempake Kecamatan Samarinda Utara. EPP , 8(2), $34-40$.

Syaparuddin, D. (2013). Kajian Pembuatan Sirup Buah Pidada Merah (Sonneratia caseolaris). Tugas Akhir. Banda Aceh : Universitas Syiah Kuala.
Wahyukinasih $\mathrm{MH}$, Wulandari C, Herwanti S. (2014). Analisis Kelayakan Usaha Berbasis Hasil Hutan Kayu Ekosistem MAngrove di Desa Margasari Lampung Timur. Jurnal Hutan Tropis, 2(2), 41-48. 